\title{
Peeking into the black box of privacy - biobank participants on the importance of recognition
}

\author{
Lars Øystein Ursin and Kristin Solum Steinsbekk \\ Department of Public Health and General Practice, NTNU, Trondheim \\ Correspondence: lars.ursin@ntnu.no
}

\begin{abstract}
Biobank research deals with personal information and data from blood and tissue analysis, making the questions of legitimate recruitment of participants and handling of their data to be intimately connected with the issue of privacy. Thus, identification of the privacy interests of biobank participants is vital to the legitimacy of biobank projects. In this article, we ask: How do participants articulate the nature of privacy issues in biobanking? Here we report from a focus group study on biobank participants' view of privacy and consent in relation to biobank research. Based on our analysis, we found that participants viewed privacy as a concept that describes several dimensions of the fundamental need to be recognized and respected as an individual and as a person. Interestingly, the needs to be recognized and respected were also viewed as the basic purpose of biobank consent.
\end{abstract}

\section{INNLEDNING}

Protection of privacy is a prominent concern in the ethics of biobanking. According to Bialobrzeski et al., this is because biobanks are on contradictory missions: "on the one hand serving the collective welfare through easy access [of resources] for medical research, on the other hand adhering to restrictive privacy expectations of people in order to maintain their willingness to participate in such research" [1, p. 9]. The sensitivity of the personal information collected from biobank participants in addition to the potential sensitive nature of results generated by the analysis of the biological samples calls for strict protection of data. To implement stringent privacy protection regimes threatens to hamper, however, the researchers' purpose of setting up a biobank, as well as the participants' in making their contributions: To facilitate the availability of large datasets of genetic and health related information from groups of people for scientific inquiry.

Moreover, progress in genomics, bioinformatics, computation and data mining increases the potential to identify persons even in an anonymised set of genetical data [2-5]. This has prompted some $[2,6]$ to advocate for a proper governance structure that regulates privacy risks in order to protect research subjects. In contrast, others [7] suggest that we should accept the potential ramifications of this situation and stop guaranteeing privacy protection for biobank participants. Thus biobank participation will be restricted to persons willing to take the risk of partly or fully disclosure of their submitted and research generated biobank information.

The legitimacy of different approaches to participant privacy protection will depend on our understanding of privacy and privacy interests. However, while the concept of consent is widely discussed in biobank ethics, the concept of privacy is black boxed: The importance of privacy protection and the right to privacy are highly emphasized, but are more often stated than discussed in biobank ethics.
This lack of discussion would be appropriate if the nature of privacy was obvious, or if a right to privacy is nothing but shorthand for more basic rights. Privacy protection in the context of biobanking could in the latter case be accomplished by protecting a more basic interest. Privacy protection could be no more than an aspect of respecting participants' autonomy, for instance. If that were the case, then to protect the privacy interests of participants would be the same as to respect their autonomy.

According to Lunshof et al.'s strategy privacy could, in fact, simply be viewed as an aspect of autonomy: Privacy protection concerns just the right of participants to control, or to forfeit the control of access to personal information. The literature on the nature of privacy, however, shows that neither the nature of privacy nor its relation to other concepts like autonomy is obvious [8-11]. Moreover, it is not easy to state clearly both what we want to protect in protecting participants' privacy, as well as why we want to protect the privacy of biobank participants [12-15].

In biobanking, privacy issues are introduced in the consent process where information about privacy risks and protection policies is given to the participant. The potential participant has thereby the opportunity to reflect on potential privacy risks and ultimately decide whether to participate or not [16]. By giving their consent the participants "waive prohibitions on actions that would otherwise be intrusive", in the opinion of Manson and O'Neill [17, p. 97].

In order to be able to discuss privacy issues, both in general and within biobank ethics, it is important to get a clearer view of what privacy means, why we think privacy should be protected, and how we regard privacy to be protected by the participants' consent. In addition, to ground legitimate consent policies and sound governance of participant data, a better understanding of what privacy entails is needed. Although ethical challenges of biobank research have been given broad attention in expert forums, even the experts 
struggle to find good ways to meet specific ethical challenges related to privacy.

The purpose of this paper is to peek into the black box of privacy by drawing on biobank participants' thoughts and insights on the issue of privacy and the related issue of consent. In this article we will present and discuss our findings from focus group interviews on the nature of privacy and consent. Knowledge of biobanks or biobank research is not widespread in the general public, as shown by a recent report on "Europeans and biotechnology" [18]. To establish a point of departure and to ensure some familiarity of biobanks amongst the discussants the focus groups were formed by participants of the Norwegian HUNT $^{1}$ study. Using HUNT biobank as a backdrop, we aimed in the focus group discussions to arrive at an understanding both of the general nature of privacy, as well as its special relevance to biobanking. In these group sessions we moved from discussions of privacy to discussion of consent, in order to clarify the interrelation between these issues.

Below we will present our approach and findings and then we briefly discuss privacy and consent in light of these findings.

\section{MeTHODS}

As part of the research project In genes we trust? Biobanks, commercialisation and everyday life, we sought to explore lay person's attitudes towards questions concerning privacy, consent, commercialisation and genetic research in biobank contexts. Conducting focus group interviews is a well-established method in qualitative research such as in applied research and evaluation $[19,20]$. This method enables us to investigate "common sense beliefs and public topoi" among lay persons [21-23] and it facilitates the exploration of how participants use their existing knowledge in discussing and making sense of potentially elusive, quite abstract and hypothetical concepts.

\section{Approval}

This study was approved by the Norwegian Data Inspectorate via the Norwegian Social Science Data Services (NSD) who handles the statutory data privacy requirements in the research community in Norway.

\section{Recruitment of participants and pre-interview preparations}

In 2010 lay persons from the county of Nord-Trøndelag were invited to participate in focus group discussions. Nord-Trøndelag is the catchment area of the Norwegian HUNT-study [24,25]. This is among the largest (population-based) health studies ever performed worldwide. [24]. This study has a thirty year long history, has been highly visible locally and has enjoyed uniquely high participation rates [24,26,27]. HUNT is publicly owned

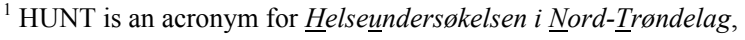
which translates into The North Trøndelag health study. and run within an academic setting. Since 1984 HUNT has conducted three rounds of recruitment from the general population of the county of Nord- Trøndelag. Blood samples were collected in the last two rounds, conducted in 1995-97 and 2006-08. This collection of samples constitutes the HUNT biobank, and has been used for medical research (from 2002 onwards) including genetic analysis.

In recruiting participants from a population where people are familiar with HUNT, our aim was to enable the focus group discussants to actively use HUNT, in addition to their general life experiences, as a point of reference when examining the topics of privacy and consent.

We strategically recruited participants to eight focus groups via local contact persons identified by members of our research group. Selection of participants aimed to represent different age groups and different geographical areas. They were recruited based on either an association with a patient interest group, public health organisation or on where they worked. For a more detailed description of this process please see [28].

To reduce feelings of stress and frustration when discussing unfamiliar topics, as we had experienced in a previous focus group study [29] as well as has been reported by Haddow et al. in a similar study [30], we offered participants a chance to prepare for the discussion by providing them with an information packet prior to the group sessions. This packet included an information leaflet about HUNT and a description of the topics and types of questions that would be discussed.

\section{The focus group session}

Standard focus group procedures as described by Krueger [30,31] were followed. A detailed interview guide with six major topics was developed in our research group ${ }^{2}$ and used in each session. Only issues pertaining to privacy and consent are reported here. Each focus group interview was moderated by two facilitators and lasted up to 2 hours. The individual topics and the main questions of each topic were introduced using a Power Point presentation. The presentation slides had headings, images and questions aimed to facilitate the discussions by providing specific and well-known starting points. All questions were open, in order to allow participants to contribute to the discussion in their own way, and to let the issues they found relevant emerge. The basic format of the group discussion was structured to facilitate conversations among the invited participants. The main questions were nevertheless actively followed up by additional enquiries from the facilitators.

The Norwegian heading of one of the focus group slides reads "Personvern og privatlivets fred". This literally translates into: "Protection of persons and private

\footnotetext{
${ }^{2}$ The research group of the "In genes we trust? Biobanks, commercialisation and everyday life"-project consists of Berge Solberg and John-Arne Skolbekken, both researchers working at NTNU, in addition to the authors of this article.
} 
life". The word personvern in the Norwegian original means "protection of information about a person", while fred means both peace and to be left alone. Thus a more accurate rendering of the heading would be: "Protection of information about a person and his ability to peacefully pursue his private life unsolicited." The three main questions posed were: "What do you consider to be sensitive information? Who decides what kind of information is sensitive? Why should one treat sensitive information with care?" Questions 2 and 3 were introduced mainly in order to facilitate a good discussion of the first question. The word sensitive is used instead of private in order to avoid the private/ public distinction, aiming to ease the participants' free assessment of what is private and why.

The issue of consent was introduced with a slide containing the heading "Informed consent" and a short paragraph informing the participants that blood and tissue samples taken for diagnostic purposes could be interesting to use in various research projects. Two questions were posed on the slide: "Does use of samples already taken for diagnostic purposes in research require informed consent?"; "How would you justify such a consent requirement?" On this topic, question 1 was introduced in order to facilitate a discussion on the second question.

\section{Data collection and analysis}

Each participant provided written consent and the sessions were digitally recorded, transcribed into full text and anonymized. The content of the responses from our discussants was analysed in an inductive manner by identifying emergent themes. The process is informed by Massey, Krueger, Mayring and Malterud [20-32-34], with an emphasis on thematic analysis. Our aim was to identify what Massey [20] describes as "themes [that] may reflect a range of individual attitudes, opinions, and beliefs, as well as touching on otherwise unarticulated norms and social values" [35, p. 22]. The analysis of the thematic content was refined in two-way discussions where the transcripts were revisited several times. The condensed results and their discussions are presented in the following sections.

\section{FINDINGS}

The focus group participants struggled to articulate what is private, and why. The discussions in all groups followed a pattern of repeated but ultimately failed attempts at arriving at a consensual and comprehensive identification of the nature of privacy. But even if it might have remained a mystery for the discussants what privacy is at the end of each session, the participants' reflections informed a more nuanced description of privacy. And even if no consensus was reached, the discussants' observations and opinions were quite succinct. They offered precise descriptions of several dimensions of privacy. These dimensions, we think, are not wholly reducible to each other. In this way, the focus group discussions suggest that privacy is a com- plex concept that cannot be understood or defined by a simple set of criteria.

Moving from a discussion of the concept of privacy to a discussion of the rationale of consent requirements, the discussants remembered clearly that they had given their consent to participate in HUNT. But why? Several reasons were offered, reasons that add up to a complex justification of consent requirements, rather than being reducible to a single justifying principle.

\section{Privacy}

Based on our analysis, the best general description of privacy given in our groups was that privacy "concerns the integrity of the individual in society at large. You should be allowed to be yourself. (...) I think that is what is at stake here at the fundamental level - it concerns the identity of persons." What does it mean that privacy is a matter of integrity and identity? We found that the discussants emphasized the following dimensions of privacy: Self-determination, harm, respect, freedom, confidentiality, and discretion.

Self-determination, often expressed as control, was the first dimension that participants identified, and it appeared to be the most important aspect of privacy in their minds. One of the participants simply defined sensitivity in terms of self-determination: "Private information is the information I want to control myself." A corollary of this definition is that the kind of information I do not want to control myself is not sensitive. This position was also expressed: "If you consider something as private, even if it is a good thing or does not matter at all, then it is not up to others to decide whether we can pass it on or not, if it is sensitive for you." Thus there are no inherently private matters, anything can be private - or not. Privacy as something strictly relative to and defined by the individual was by several discussants taken to justify - or at least explain - that each person has a zone of privacy that is idiosyncratic: "We all have different zones, I should say, some people keep others at a greater distance [than others]."

However, the definition of privacy in terms of selfdetermination was indirectly questioned by other participants: "A lot of people place information about themselves [on a webpage] without any thought of how sensitive it is". Such a statement would not make any sense if every individual is the final arbiter of what is sensitive or not. For this statement to make sense, it must either be the case that some kinds of information are inherently sensitive, or that we can judge whether something is sensitive for someone else. Both of these conditions are touched on in the following excerpt from the transcription:

$\mathrm{M}$ (moderator): The first topic is protection of persons and private life, and there we have put up some pictures and then the question is what do you consider to be sensitive information?

7: Personal health information, what is the matter with us and these things...

(...) 
3: That will depend a bit on... if it is someone else that has posted it and you suddenly realize that you are depicted on a public page without any consent then it is a totally different matter than if you have provided the information on your own Facebook-page.

(...)

6: You mentioned Facebook or other websites where a lot of people place information about themselves without any concern of the sensitivity of it, at the time, but might regret it later on.

The participants here discuss a more complex view of privacy, where self-determination is important, but not the sole criterion for what is deemed sensitive and therefore needs to be kept private.

Potential harm was also voiced as an important dimension of privacy. Of course, not any harm will do. That I have tripped and injured my knee playing soccer would not by itself classify as a private matter. It must be a harm related to personal health information i.e. harm that is harmful for the integrity of the person. Here we are back to privacy as identity, meaning that private matters might be harmful to your moral character or social role, to who you are - or are perceived to be.

The harm condition is highlighted by the remark on the sensitivity of the different kinds of information transfer involved in biobank participation: "I think that what I give away in a conversation [or a questionnaire] is much more sensitive than that blood. (...) Yes, because it relates to something about me." Other participants thought that genetic information was very private. The private character of genetic material generally depended on the chance of misuse of genetic information.

Thus anonymisation of personal data, the use of aggregate data at a group level or use of data in relation to non-stigmatizing diseases, made the genetic material lose or not acquire a private nature. However the collection and collation of information that is not private on its own can make it sensitive: "Information can become sensitive if someone goes out and gathers a lot of information that is not sensitive, but that becomes sensitive if you put it together and make a profile on people, then all of a sudden it can turn into something nasty and sad." The private nature of genetic material is thus not inherent, but dependent on the use to which it is put, how it is put together, and the risks involved.

Nevertheless, the participants thought that being included in a biobank, that is the very act of giving away any information, was a matter of self-determination. This indicates the respect dimension of privacy. The ontological aspect - and immense importance of guarding and keeping a private sphere is beautifully captured in the following dialogue on why potential biobank participants should be asked for their consent:

4: It has something to do with your self-image (...) that I am self-determined.

1: That I am the master of my domain.

4: Yes, that I do not dissolve into nothingness, and that everyone can help themselves to what's mine. (...) It has something to do with respect.
If a person's private sphere is not respected, the very social existence of that person is threatened. To be approached as person, not as a mere research object, is a matter of being respected. The dimension of respect is important to guard against an all-encompassing existential harm, and to be recognized as a fellow citizen taking part in a shared moral and political realm.

The freedom dimension of privacy is expressed in the interest in positively creating your own self-image: "In a way, you want to decide for yourself who you are, and not be defined by others from what they hear and know from other sources". The participants recognized a need to be free from social control, and also to be able to free yourself from the past: "I do not google myself all that often, but in fact I did yesterday and then (...) some old stories popped up that I think should have been passed over in silence today."

The freedom dimension of privacy emphasizes an interest in being a dynamic and to some extent an elusive person. This dimension has a clear strategic aspect, like the possibility to apply for a job in all confidentiality, in order to avoid speculation and unsettling questions from you current colleagues and employer: "Doesn't she like it here?" The freedom dimension of privacy highlights a person's interest in being a selfdefined agent writing his or her own story: “... in a way you want to decide yourself who you are going to be, instead of from what others hear and know about you from other sources". And at the most fundamental ethical level, the possibility to create a room where you are free to move and act without the others being able to completely predict, track, and explain your movements is a basic condition for being (regarded as) a moral agent at all.

The confidentiality dimension was expressed by the participants both in a narrow and a broad sense. The narrow sense is a matter of you telling someone something of a private nature about yourself that you expect them to keep to themselves or within the relevant group, or that someone finds out something about you that you expect them not to tell anyone else than you or members of the relevant group. "... I have an expectation that it [information or biological materials] should be treated in a certain way (...) as in a relationship of confidentiality". These relations of confidentiality form the basis for how and why we involve ourselves with others: "(..) in a family some information will be considered to be sensitive outside but not inside of the family. In health related questions, some information can be sensitive for everybody except my doctor (...)".

In the broad sense, confidentiality is a matter of trusting others to treat you with respect and not ruin your private realm: "(...) it is about respect for the one you get information about (...)". Others have a duty not to harm you, and to leave you some elbow room in social space. We depend on others in general to uphold our private realm, to trust the ones we enter specific relations of confidentiality with: "The interpersonal 
relationships of trust are important here. If you violate such a relationship, then ok another person will lose trust in you. But he might also lose trust in other people, and in that way you will do much greater harm." Here the interpersonal nature of privacy is emphasized, not just in the way that my explicit wish to keep something private should be respected, but that there is an obligation on the confidant to assess what is private or not in different social settings.

The final dimension of privacy we identified in the focus group discussions is discretion. Discretion here concerns the duty of the individual to keep her own private matters out of the public sphere. The cultural and temporal aspect of the discretion dimension emphasizes that what is considered improper to talk about is relative to time and place:

1: Yes, if you look back 30-40-50 years, cancer and all those things should not be talked about; it was all taboo those days.

6: But there has been a change lately, taking place in the last 4-5 years, making things very personified, I feel, meaning that each individual person has been given all the responsibility for her own development (...)

The discretion dimension has a political aspect that connects to the possibility of harm: “(..) to express your political point of view is not a problem in Norway, but there are other places in the world where that is very problematic (...). "The cultural and temporal aspect of discretion emphasizes both that the border is dynamic, and that privacy is more than just a residual category but is a cultural construction upheld by social ideals of personhood, tolerance and subcultures. The concepts of the private and the public are defined by each other.

\section{Consent}

Turning from privacy and sensitivity toward consent in biobank research, it is interesting to note the reappearance of the dimensions they had discussed in relation to the issue of privacy. The discussion of consent revolved around how individuals relate to each other, to the biobank institution, and the state. The basic question seemed to be: How do we create the kind of society we want to be a part of? Here respect, trust, selfdetermination and ownership were the predominant motivations given for consent requirements.

The respect dimension loomed large among our discussants as a basic justification for requiring informed consent. When asked by the moderator in one of our focus groups: "Given the current Norwegian system [publicly funded research with the approval of regional ethical committees], do you think it would be okay if the general rule was that there was no consent requirement for this type of use [research on de-identified samples]?", the discussion continued like this:

1: That would be fine by me; it would be okay that no consent was required.

2: I think that, you would feel a bit, you would feel a bit better if you have given your consent, right?

5: A bit more important..
2: Yes, a bit more important in the big picture, I think. It really does not matter for me as a person [to give my consent], but that feeling might be a part of it.

M:But what is it a feeling of?

2: That you are a bit more important in the system, that you take part and contribute in a better way.

1: That you are respected.

2: That you are taken seriously and not just tossed in.

Even though a clear sentiment in many of our groups was that consent is not always necessary, they all had an unambiguous understating that consent relates to respect. As we can see from this excerpt of the discussion, the kind of respect participants were concerned about had to do with recognition: To be viewed as a distinct person rather than just a faceless donor. The obligation to ask for participants' consent in this perspective stems from a corresponding right to be treated as a person, rather than a corresponding right to selfdetermination. To be asked for consent is important as a matter of courtesy, rather than as matter of individual autonomy:

4: That kind of question, it is, I think it's like, most people answer yes. But there will always be some people that..

?: Weirdoes ((laughter))

4: Yes, one expects that people answers yes to this [to take part in HUNT].

$\mathrm{M}$ : What do you think about duty here? Is it almost like a duty?

3: Yes. It's a bit like a duty.

2: There is a factor there, yes.

These discussants voiced a mild moral duty to take part that was present in all our groups, and the respect dimension should be understood in relation to this. The participants are happy to take part, and the researchers should show their gratitude in treating the participants in a decent way: "I think this has to do with good manners, to ask for permission to use it [a tissue sample]".

The respect dimension borders to the trust dimension of consent. In asking for participants' consent, researchers show that they are people who can be trusted to handle participants' contributions in a decent way: "You might feel a bit more assured that it [a blood sample] in good hands, too, if they ask for your consent, that it's not totally let loose." The biobank institution and relevant governing bodies also becomes more trustworthy in openly asking for consent, rather than potentially leaving participants wonder what is going on with their samples. Some discussants expressed that consent enhanced trust in involving the participants in the ongoing biobank research in a proper way: "If you have to get consent from people you have to argue (...) I think it is very good that you have to argue why this research is important." Even if the discussants did not question the ethical standard of HUNT research, they emphasized the importance of HUNT to be totally open about their research.

Although the discussants generally viewed HUNT participation as a mild moral duty, they did not think participation should be mandatory. Thus they did not argue for a legal duty to take part. In accordance with this they viewed consent as an indispensable tool for 
participants' self-determination: "Nobody knows when it's okay for us [to have one's samples included in research]. We might have differing views on when it's okay or not." Some discussants thought that it was important in principle to limit states' ability to gather biobank data on citizens without participants' permission: "It has something to do with the respect for the individual (...) he/she is supposed to be both sacrosanct and autonomous, this is what this is all about".

The discussants were quite divided on the question of ownership to their contributed genetic and health related information. Some expressed some form of ownership relation to their blood samples, in line with the policy of HUNT in regarding the participants as the owners of the samples in the sense of being the ones who can ask for their withdrawal from the biobank at any time. Other discussants had no more relation of ownership to their samples, than to the hair cut off at the hairdressers. An important reason for their offhand rejection of ownership is the anonymity of the samples used in HUNT research projects: "As long as they don't use names or, it's just a number and then I don't think it [to ask for consent] is important. It's almost like donating your body [when you do not need it any more]." In this analogy, the samples cease to be a part of a living person when they are donated, and becomes like mere organs suitable to help other persons.

\section{DISCUSSION}

The focus group discussions brought forth a heterogeneous description of the nature of privacy. This correlates well with the arguments from Daniel Solove [36,37]. Inspired by Ludwig Wittgenstein [37], he describes privacy as a concept dealing with phenomena that has family likenesses rather than a common core: Privacy is like a family and has dimensions instead of characteristic family traits. And like family traits, the dimensions of privacy makes situations resemble one another in a way that makes it natural to keep them together. What makes family members resemble one another is however not one common trait, but rather overlapping likenesses, like some individuals sharing a long nose, while others share a small mouth. What makes situations of privacy concern resemble one another is likewise not one single criterion, but overlapping likenesses.

The overlapping dimensions of privacy expressed by our discussants are summed up in the six dimensions of self-determination, harm, respect, freedom, confidentiality, and discretion. Initially, self-determination and harm was at the forefront of the discussions of privacy. What is private was partly seen as something I decide myself, and both actual breach of privacy as well the worry of breach of privacy can harm me as a person. However, as the discussions progressed, and the participants described the different situations where privacy concerns are involved, they had to make use of one or more of the six dimensions mentioned above. The heterogenic nature of privacy in various contexts, as well as its varying importance for different people, largely explains why it was difficult for our participants to describe the privacy issues at stake in a short and concise manner. In addition, the participants expressed rather different levels of concern for their own privacy and to what degree of risks they could accept.

HUNT participants had accepted the risks and felt that their privacy was both respected and protected by the governing structure of HUNT. For them, the crucial points were that they could control whether to participate or not, and that the potential for breach of privacy was kept to a minimum. Although they all felt that contributing personal information to biobank research had something to do with privacy all but two were still part of the biobank endeavour. This can be said to correlate with findings in a previous quantitative study by Kaufman et al. [16] which shows that even though one has concerns for breach of privacy one still is willing to participate. Their study showed that $90 \%$ of the respondents were concerned about privacy in the biobank context yet $84 \%$ supported the general idea of large cohort studies and $60 \%$ said that they definitively or probably would participate.

In a couple of groups the policy chosen for the Personal genome project (PGP) [7] was discussed. The PGP policy entails full disclosure of research participants' personal information and analytical results via the internet. As HUNT promises privacy and confidentiality in the consent process his strategy was alien to the discussants, and strongly questioned. Again, privacy protection was seen to be vital. Not necessarily vital in the sense of protection against harms, as they perceived the risk of harm as minimal in the current Norwegian society, but vital in the way of showing respect for their participation and of themselves as individuals.

As stated in the introduction, the participants encounter privacy issues through the consent process. Consent has been a cornerstone of ethical conduct in medical research during the last decades. But it still remains controversial what constitutes a valid consent, when consent is necessary and in which form it should be issued and used. This is also the case in biobank research [17,39-41]. Against the background of this controversy as well as the intimate link between privacy and consent we wanted to get insights from actual biobank participants on their views of what consent represent to them. Our aim in this study was not to discuss the legitimacy of various types of consents in biobank research. Nevertheless, it is interesting to note that our discussants saw consent to accommodate a number of purposes. Spelling out these purposes is an aid in showing us why the issue of consent, like privacy, is a complex and challenging one for biobank research.

The participants highlighted the dimensions of respect, trust, self-determination and ownership. The importance of respect and recognition was voiced in all 
our focus groups. This is also seen in a recent paper from Simon et al. [42] where the sentiment from their informants were that to "ask for consent" is needed in biobank research, this is "the right thing" to do, and necessary to honour respect. In addition to being shown respect by requesting participants' consent, the participants are given recognition and granted access to information. Thereby, they are put in position to assert some kind of control, and are recognised as independent and reflecting individuals and not mere members of the masses.

For our discussants, to be recognised as a person provides a social obligation on the part of the researcher to treat the participants in a decent way. If the image of the person is lost, it is easier to let go of one's ethical standards. Of course, the participants paradoxically express just the opposite wish; to be nothing but a faceless donor in a de-identified biobank. But this air of paradox is dissolved once we remember the point of anonymity; to protect the interests of a person.

In the context of biobanking, the promise of anonymity was seen as essential but nevertheless taken for granted by many of the discussants. Interestingly neither our discussants nor we brought a scenario of breach of confidentiality in HUNT into the discussions. This most likely reflects previous findings by Antonsen [43] in an earlier qualitative focus group study where the discussants voiced strong trust that HUNT would not breach confidentiality. They deemed breach of confidentiality to be a threat to privacy and would therefore clearly be detrimental to their trust in HUNT [43]. However, privacy dimensions such as confidentiality did not seem to be decisive for whether a person participates in HUNT or not.

On the one hand, discussants in our study expressed the interest of the individual in being able to abstain from or to withdraw from biobank participation. On the other hand, they expressed the participants' interest in being able to be involved in, informed of, and benefit from biobank participation. These dual interests of biobank participants are emphasized by Mats Hansson: "In order to deal with the challenges in the social complex world of human beings, great demands are placed on the capacity of individuals, both to protect their own perspective and also to protect their participation with others" [9, p. 152].

Society and its citizens share this dual interest: The private sphere of the individual must be protected in order to enable him and her to be a moral person and be protected from "dissolving into nothingness". At the same time society must be tolerant and safe in order to make the individual able to take part instead of having to retreat into a private realm.

To protect the privacy of biobank participants by anonymity is a way to prevent harm to participants and protect their dignity. Anonymity protects participants' dignity by keeping their biobank information out of sight for the public eye. Harm or loss of dignity redu- ces the freedom of persons to lead their lives the way they want to. Anonymity gives the participants the freedom to realise their interest in contributing to biobank research. At the same time, as suggested by the discretion dimension of privacy, increased tolerance in society towards currently stigmatizing information about individuals is another way of protecting their dignity.

Interestingly, our discussants touched upon the notion that the requirement of consent forces the research institutions and the researchers themselves to think through the purposes and ramifications of their activities. To know that the process leading up to the making of the consent form has taken place in the biobank institution was expressed by an informant as by itself reassuring for the participants. The awareness of such a process can be seen as more vital to the trustworthiness of the biobank than the act of signing the consent form for the individual. Several discussants viewed a transparent organisation and easy access to information for participants as sufficient for biobank recruitment purposes. Thus the crucial part of informed consent was information rather than consent.

In giving their consent, participants waive their right not to contribute data and samples to the biobank. They are given the opportunity not to consent. Interestingly this aspect was only minutely touched upon in our discussions. The contrary sentiment seemed more important; that asking for consent actually makes the research endeavour more accountable by showing respect for the contributor. In this way the discussants spoke of redeeming a feeling of control, of being respected and reassured - because they have been given the opportunity to consent.

\section{CONCLUDING REMARKS}

Our focus group discussants arrived at a complex view of the nature of both privacy and consent. They emphasized several dimensions of privacy; selfdetermination, harm, respect, freedom, confidentiality, discretion, and of consent; respect, trust, selfdetermination, ownership. The importance of privacy protection was strongly advocated, for a complex set of reasons. The paramount purpose of asking for consent was to show respect, and in order to respect biobank participants' privacy its non-reducible dimensions should be taken into account. In the era of globalisation, data mining and data sharing, in general and in medical research in particular, increased threats to privacy are envisioned. To be able to still conduct good medical research, to be able to recruit participants in for example to biobank research it is important to be aware of, discuss, assess and reduce such threats. This requires an understanding of the complex nature of privacy and the role of consent in medical research in general and in biobank research in particular. 


\section{REFERENCES}

1. Bialobrzeski A, Ried J, Dabrock P. Privacy revisited? Old ideals, new realities, and their impact on biobank regimes. Poiesis Prax 2011; 8: 9-24.

2. Heeney C, et al. Assessing the privacy risks of data sharing in genomics. Public Health Genomics 2011; 14 (1): $17-25$.

3. Lowrance WW, Collins FS. ETHICS identifiability in genomic research. Science 2007; 600: 602.

4. Homer $\mathrm{N}$, et al. Resolving individuals contributing trace amounts of DNA to highly complex mixtures using high-density SNP genotyping microarrays. PLoS Genet 2008; 4 (8): e1000167.

5. McGuire AL, Gibbs RA. No longer de-identified. Science 2006; 312 (5772): 370.

6. Austin LM, Lemmens T. Privacy, consent, and governance. New challenges for biobanks: Ethics, law and governance, 2009.

7. Lunshof JE, et al. From genetic privacy to open consent. Nature Rev Genet 2008; 9 (5): 406-410.

8. Solove DJ, Schwartz PM. Privacy, information, and technology. Aspen Law \& Business, 2008.

9. Hansson MG. The private sphere: an emotional territory and its agent. Springer Verlag, 2007.

10. Schoeman FD. Philosophical dimensions of privacy: An anthology. Cambridge University Press, 1984.

11. Rössler B, Glasgow RDV. The value of privacy. Polity Press, 2005.

12. Rothstein MA. Genetic secrets. Yale University Press, 1997.

13. Laurie GT. Genetic privacy: a challenge to medico-legal norms. Cambridge University Press, 2002.

14. Ursin L. Biobank research and the right to privacy. Theor Med Bioeth 2008; 29 (4): 267-285.

15. Ursin L. Privacy and property in the biobank context. HEC Forum 2010; 22 (3): 211-224.

16. Kaufman DJ, et al. Public opinion about the importance of privacy in biobank research. Am J Hum Genet 2009; 85 (5): 643-654.

17. Manson NC. Rethinking informed consent in bioethics. Cambridge University Press, 2007.

18. Gaskell G, Gottweis H. Biobanks need publicity. Nature 2011; 471: 159-160.

19. Morgan DL. Focus groups as qualitative research. Sage Publications, 1997.

20. Massey OT. A proposed model for the analysis and interpretation of focus groups in evaluation research. Eval Program Plann 2011; 34 (1): 21-28.

21. Schweda M, Schicktanz S. Public ideas and values concerning the commercialization of organ donation in four European countries. Soc Sci Med 2009; 68 (6): 1129-1136.

22. Bohnsack R. Rekonstruktive Sozialforschung: Einführung in qualitative Methoden. Vol. 8242. 2007: Budrich.

23. Levitt M, Weldon S. A well placed trust?: Public perceptions of the governance of DNA databases. Critical Public Health 2005; 15 (4): 311-321.

24. The HUNT study - a longitudinal population health study in Norway. http://www.ntnu.edu/hunt.

25. Holmen J, et al. The Nord-Trøndelag Health Study 1995-97 (HUNT 2): objectives, contents, methods and participation. Norsk Epidemiologi 2003; 13 (1): 19-32.

26. Holmen J, et al. Attitudes to genetic epidemiology-illustrated by question for re-consent to 61,426 participants at HUNT. Norsk Epidemiologi 2004; 14: 27-31.

27. Johnsson L, et al. Hypothetical and factual willingness to participate in biobank research. Eur J Hum Genet 2010; 18: 1261-1264.

28. Steinsbekk KS, et al. We're not in it for the money-lay people's moral intuitions on commercial use of 'their' biobank. Medicine, Health Care and Philosophy 2011: 1-12.

29. Skolbekken JA, et al. Not worth the paper it's written on? Informed consent and biobank research in a Norwegian context. Critical Public Health 2005; 15 (4): 335-347.

30. Haddow G, et al. Tackling community concerns about commercialisation and genetic research: a modest interdisciplinary proposal. Soc Sci Med 2007; 64 (2): 272-282.

31. Krueger RA. Focus group kit. Vol. 6, Analyzing \& reporting focus group results. Sage publications, 1998.

32. Krueger RA. Moderating focus groups. Sage Publications, 1998.

33. Mayring, Qualitative content analysis. Citeseer, 2000.

34. Malterud K. Kvalitative metoder i medisinsk forskning, 2. utg. Oslo: Universitetsforlaget, 2003.

35. Kamberelis G, Dimitriadis G. Focus groups: Strategic articulations of pedagogy, politics, and inquiry. The Sage handbook of qualitative research, 2005; 3: 887-907.

36. Solove D. Understanding privacy. Harvard University Press, May 2008.

37. Solove DJ. Conceptualizing privacy. California Law Review 2002: 1087-1155.

38. Wittgenstein L, Hacker PMS, Schulte J. Philosophical investigations. John Wiley and Sons, 2009.

39. Hofmann B. Broadening consent - and diluting ethics? J Med Ethics 2009; 35 (2): 125.

40. Caulfield T, Kayet J. Broad consent in biobanking: reflections on seemingly insurmountable dilemmas. Med law Int 2009; 10 (2): 85-100.

41. Sheehan M. Can broad consent be informed consent? Public Health Ethics 2011; 4: 226-235.

42. Simon CM, et al. Active choice but not too active: Public perceptions on biobank consent models; Genet Med 2011; 13 (9): 821-831.

43. Antonsen S. Motivasjon for deltakelse i helseundersøkelser. Norsk Epidemiologi 2009; 15 (1): 99-109. 